\title{
The surgeon's role in molecular biology
}

\author{
Gaetano Rocco, MD, FRCSEd, FECTS
}

\begin{abstract}
The biomolecular era is rapidly becoming shaped around the supreme interest in targeted therapy for patients with non-small cell lung cancer. Tissue analysis has become crucial in the definition of biomarkers and genomic signatures able to predict the response to treatment or even survival. Lung screening programs and minimally invasive thoracic surgery are jointly aimed at increasing the quantity and quality of specimens of non-small cell lung cancer caught at the earliest stages with the attendant, significant, effect on patient survival. In addition, biomolecular researchers are disclosing an ever-increasing cohort of patients with specific genetic mutations that make their cancer susceptible to individualized treatment. When needed for immunohistochemical characterization, investigators are ready to request "research biopsies" to consolidate tissue availability for clinical trials, translational research, and in biobanks. With unique and diverse tools in the surgical armamentarium, the thoracic surgeon plays a central role in this new multidisciplinary professional environment, actively participating in creating the foundations of the biomolecular era. (J Thorac Cardiovasc Surg 2012;144:S18-22)
\end{abstract}

With more than 220,000 and 155,000 new cases of lung cancer and deaths from the disease estimated to occur in the United States, one can assume that the role of the thoracic surgeon in the molecular biology era of lung cancer management will be as central as it could have ever been. ${ }^{1}$ Among all cancers, lung cancer ranks second and first in terms of the incidence and mortality in both genders. Recently published data have demonstrated that, in the male population, lung cancer contributes to the decrease in all cancers in the United States by $38 \%$ owing to smoking cessation policies implemented in the past. ${ }^{1}$ Nonetheless, the issues of gender discrepancy and the development of lung cancer in never smoker will polarize the attention of clinicians and researchers for the foreseeable future. ${ }^{2}$ In this setting, collaborative institutional efforts are underway to routinely search for prevalent genomic alterations in the available tissue specimens. By the extensive resort to endobronchial ultrasonography, endoscopic esophageal ultrasonography, and video-assisted thoracic surgery to integrate mediastinoscopy and mediastinotomy, thoracic surgeons are expected to provide a determinant contribution to provide tissue samples for biomolecular identification in the context of multicenter biobanks. ${ }^{3,4}$ As an example, the National Cancer Institute has endorsed the creation of the Lung Mutation Consortium, a collaborative project involving several academic institutions in the United States aimed at identifying 13 molecular alterations in

From the Division of Thoracic Surgery, Department of Thoracic Surgery and Oncology, National Cancer Institute, Pascale Foundation, Naples, Italy.

Disclosures: Authors have nothing to disclose with regard to commercial support.

Presented at the 3rd International Minimally Invasive Thoracic Surgery Summit, Boston, Massachusetts, October 7-8, 2011

Received for publication Sept 27, 2011; revisions received March 21, 2012; accepted for publication June 5, 2012; available ahead of print June 28, 2012.

Address for reprints: Gaetano Rocco, MD, FRCSEd, FECTS, Division of Thoracic Surgery, Department of Thoracic Surgery and Oncology, National Cancer Institute, Pascale Foundation, Naples, Italy (E-mail: Gaetano.Rocco@btopenworld.com). $0022-5223 / \$ 36.00$

Copyright (c) 2012 by The American Association for Thoracic Surgery http://dx.doi.org/10.1016/j.jtcvs.2012.06.007 patients with non-small cell lung cancer (NSCLC) and construct trials investigating targeted therapy models. ${ }^{2}$

\section{EFFECT OF BIOMOLECULAR ANALYSIS ON PROVISION OF CARE AND EARLY DIAGNOSIS OF LUNG CANCER}

The heterogeneity of the provision of care and the lack of standardization in the treatment of patients with lung cancer have led to the implementation of collaborative models in clinical practice based on a multidisciplinary approach. ${ }^{4,5}$ Earlier detection through screening programs designed for high-risk populations combined with biomolecular identification and staging appear today to be the main thrusts behind the innovation in research and clinical management of lung cancer. ${ }^{6} \mathrm{~A}$ recently published well-designed, large $(>53,000$ participants randomized in 2 screening modality arms, with $>26,000$ patients each) screening trial (National Lung Screening Trial) comparing low-dose computed tomography screening and chest radiography yielded a $20 \%$ relative reduction in the mortality from lung cancer in the computed tomography group. ${ }^{6}$ Of the 1060 patients with confirmed lung cancer, $57 \%$ had early-stage disease (stage I and II according to the 6th edition of the American Joint Committee on Cancer staging system). When compared with that reported in the general US population, a reduction in surgical mortality in the National Lung Screening Trial ${ }^{6}$ was observed (from $4 \%$ to $1 \%$ ). Admittedly, the surgical outcomes correlated with the success of the screening program. ${ }^{6}$ Thus, the quality of the surgical care becomes 1 of the factors affecting the quality of screening trials, as does the potential for overdiagnosis (defined as the possibility of detecting cancers that would have never become symptomatic), radiation-induced health hazards, and costeffectiveness. ${ }^{6}$ With the design and implementation of screening trial programs aimed at addressing these issues to finally outline the selection criteria for screening highrisk populations, the role of the thoracic surgeon should be central in the diagnostic and therapeutic pathways of 


\section{Abbreviations and Acronyms}

ALK = anaplastic lymphoma kinase

EGFR = epidermal growth factor receptor

NSCLC $=$ non-small cell lung cancer

earlier stage lung cancer. The real question is not about the use of our expertise today-rather, it is about for how long this expertise will be needed. ${ }^{3}$ Answering this question might entail a re-assessment of both the quantitative and the qualitative aspects of the thoracic surgical profession.

\section{MOLECULAR BIOLOGY FOR THORACIC SURGEONS}

It all started with the issue of "not otherwise specified" lung cancer and the quest to avoid this inconclusive definition to facilitate targeted treatment of patients with lung cancer. ${ }^{7}$ We were familiar with the distinction between small- and non-small cell lung cancer, and we learned that a histotype-specific (squamous vs nonsquamous) combination of chemotherapeutic agents could improve longterm survival. ${ }^{7}$ More recently, along the line of translational research profiles in breast and colon cancer, ${ }^{2}$ a set of biomarkers has been identified that are used to stratify patients with lung cancer into prognostic categories ${ }^{8}$ (Table 1). In addition, some of these biomarkers might serve the purpose of substratifying patients with lung cancer according to the response to specific, currently available chemotherapeutic agents. ${ }^{9}$ National cooperative groups focused on cancer management have already integrated this information into their current decision algorithms. ${ }^{9}$ From a clinical standpoint, the expression patterns in tissue samples of mutations of epidermal growth factor receptor (EGFR), k-ras, and, more recently, translocations of echinoderm microtubuleassociated protein-like 4 and anaplastic lymphoma kinase (ALK) gene are being added to routine histotype characterization of surgical specimens from patients selected according to tumor histotype, gender, age, ethnic origin, and smoking history. ${ }^{10}$ EGFR mutations have been detected in up to $15 \%$ of white and $40 \%$ of Asian populations. ${ }^{2}$ In contrast, ALK translocations are observed in up to $5 \%$ of patients with NSCLC. ${ }^{10}$ Recently, at least $10 \%$ of patients with NSCLC have been found to have c-met (a protooncogene encoding hepatocyte growth factor receptor characterized by tyrosine kinase activity) mutations. ${ }^{10}$ The clinical correspondence lies in the remarkable control rates using targeted agents, including tyrosine kinase inhibitors, such as erlotinib and gefitinib $(60-80 \%$ in patients with EGFR mutations ${ }^{2}$ ), and crizotinib, an ALK and c-met inhibitor $(90 \%$ in patients with NSCLC with the translocation detected by fluorescent in situ hybridization ${ }^{10}$ ) (Figure 1).
TABLE 1. Molecular abnormalities in NSCLC

\begin{tabular}{|c|c|c|c|}
\hline \multirow[b]{2}{*}{$\begin{array}{c}\text { Molecular } \\
\text { abnormality }\end{array}$} & \multicolumn{2}{|c|}{ Frequency $(\%)$} & \multirow[b]{2}{*}{$\begin{array}{c}\text { Clinical } \\
\text { implications }\end{array}$} \\
\hline & White & $\begin{array}{c}\text { East } \\
\text { Asian }\end{array}$ & \\
\hline EGFR mutation & 10 & 30 & Sensitivity to EGFR TKIs \\
\hline $\begin{array}{l}\text { EGFR increased } \\
\text { copy number }\end{array}$ & 30 & 60 & $\begin{array}{l}\text { Conflicting data on sensitivity } \\
\text { to EGFR TKIs and } \\
\text { monoclonal antibodies }\end{array}$ \\
\hline MET amplification & 5 & 20 & $\begin{array}{l}\text { Resistance to EGFR TKIs; } \\
\text { indicates worse prognosis }\end{array}$ \\
\hline MET mutation & 3 & 3 & $\begin{array}{l}\text { Might be involved in EGFR } \\
\text { resistance }\end{array}$ \\
\hline EML4-ALK fusion & 5 & 7 & Sensitivity to ALK inhibitors \\
\hline k-ras mutation & 10 & 30 & $\begin{array}{l}\text { Associated with smoking, } \\
\text { indicates worse prognosis }\end{array}$ \\
\hline HER2 mutation & 3 & 10 & Resistance to EGFR TKIs \\
\hline $\begin{array}{l}\text { PIK3CA } \\
\text { amplification }\end{array}$ & 12 & 12 & $\begin{array}{l}\text { Might be involved in RGFR TKI } \\
\text { resistance }\end{array}$ \\
\hline PIK3CA mutation & 2 & 13 & $\begin{array}{l}\text { Might be involved in EGFR TKI } \\
\text { resistance and might predict } \\
\text { response to PI3K/AKT/mTOR } \\
\text { inhibitors }\end{array}$ \\
\hline BRAF mutation & 3 & 3 & Associated with smoking \\
\hline $\begin{array}{l}\text { IGF-IR increased } \\
\text { copy number }\end{array}$ & 27 & 27 & $\begin{array}{l}\text { Indicates better prognosis in } \\
\text { operable NSCLC }\end{array}$ \\
\hline
\end{tabular}

Noteworthy is the mutual exclusivity of the genetic alterations, which appear extremely rarely, if at all, in the same patient with lung cancer. ${ }^{10}$ What about the predominant proportion of patients with NSCLC who do not present with such genetic mutations? Reportedly, the association of cetuximab (an EGFR monoclonal antibody) and current chemotherapeutic regimens in patients with intense immunohistochemical staining for EGFR might yield an overall survival advantage compared with chemotherapy alone. ${ }^{11}$

Recently, in line with the observations from the outcomes of translational research of other primary cancer types, the concept of lung carcinogenesis as a process induced in the bronchial epithelium through a sequence of superimposed genetic mutations (ie, EGFR, k-ras, p53, ALK) has been described. ${ }^{2}$ From this stepwise, progressive malignant transformation, the present views on the distinction among lung cancer histotypes are being revisited. ${ }^{2}$ These histotypes, albeit all arising in the lung, are thought to be fundamentally different at a molecular level. ${ }^{2}$ A practical implication of this novel molecular interpretation has yielded the clinicopathologic distinction of adenocarcinomas into lepidic and solid growths, each entailing a different prognostic outlook. ${ }^{12,13}$ Moreover, in this biomolecular prognostic model, p16 gene inactivation, EGFR mutation, and k-ras mutation occur early in carcinogenesis, and p53 mutation, loss 


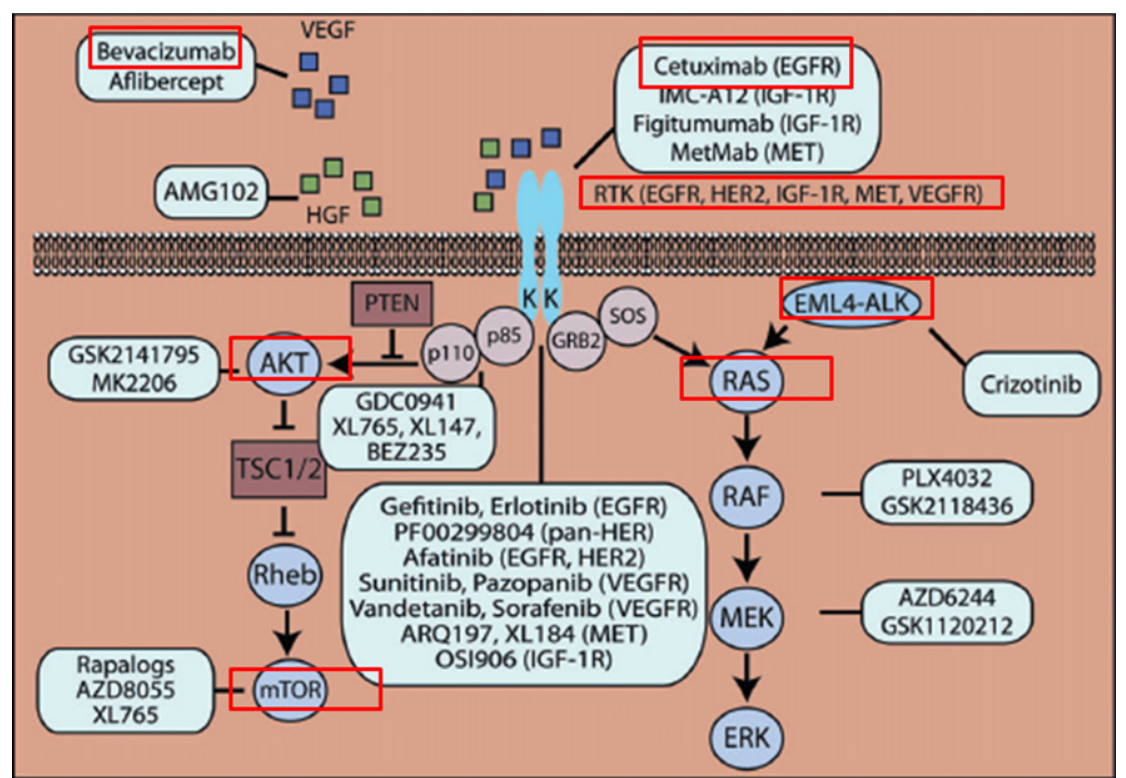

FIGURE 1. Genetic foundations of individualized therapy. AMG102, humanized monoclonal anti-HGF IgG; EML4-ALK, echinoderm microtubuleassociated protein-like 4/anaplastic lymphoma kinase; $I G F-1 R$, insulin-like growth factor 1 receptor; $I M C$-AT2, cixutumumab (humanized recombinant

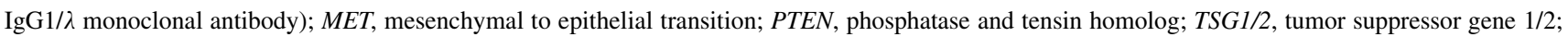
$V E G F$, vascular endothelial growth factor; VEGFR, VEGF receptor. Reprinted with permission from Janku and colleagues. ${ }^{15}$

of heterozygosity, and other genetic abnormalities develop late and correlate with invasive adenocarcinoma (Figure 2). ${ }^{12}$ In addition, genomic signatures are being studied to understand the biomolecular changes induced by tobacco smoking. ${ }^{2}$ In particular, polymorphism variants of the nicotinic acetylcholine receptor $\alpha$ - (CHRNA5 and CHRNA3) and $\beta$ - (CHRNB4) genes and glutathione transferases (glutathione transferase- $\mu, \theta$, and $\pi$ ) seem to be related to the development of lung cancer owing to the enhanced susceptibility to tobacco byproducts. ${ }^{2}$ Genomic signatures are also being studied to understand the trends of age and gender-specific outcomes in patients with NSCLC. ${ }^{14}$ As an example, Mostertz and colleagues ${ }^{14}$ attempted to create a prognostic model of disease-free survival by correlating the expression of tumor biology through the activation of oncogenic pathways (including, among others, EGFR, $\beta$-catenin, Ras, Myc, Src, tumor necrosis factor, chromosomal instability, epigenetic changes, stemness,

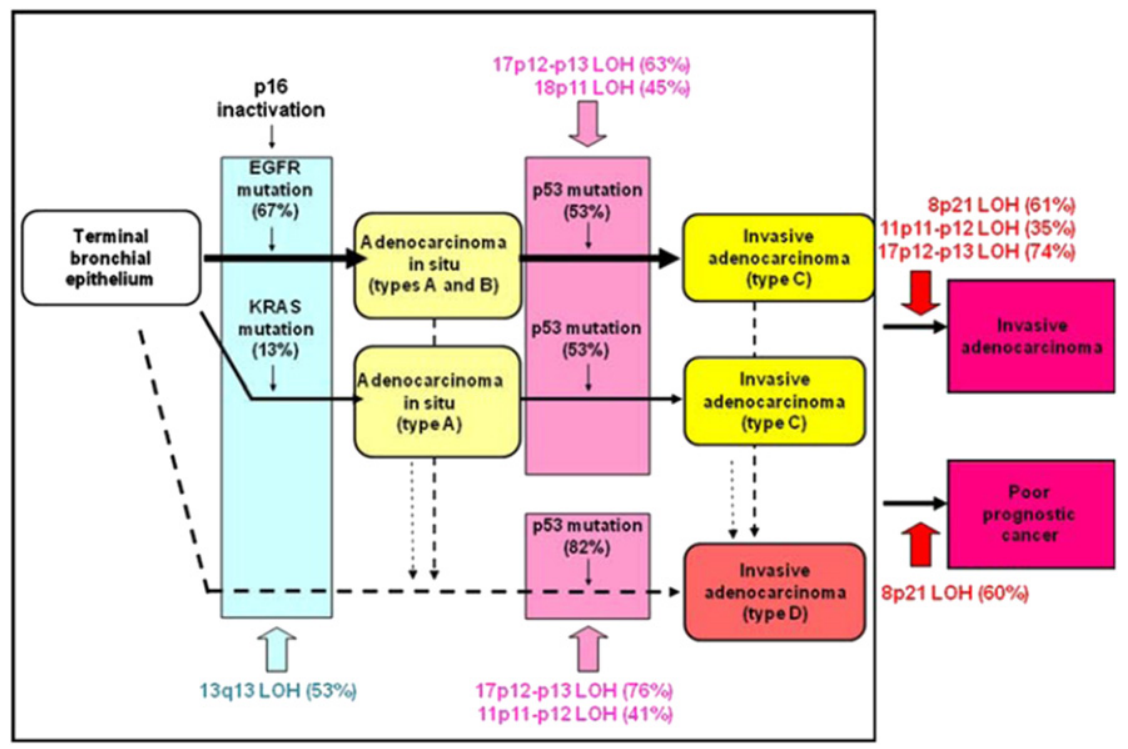

FIGURE 2. Sequential superimposed genetic abnormalities leading to carcinogenesis (adenocarcinoma). $\mathrm{LOH}$, Loss of heterozygosity. Reprinted with permission from Noguchi and colleagues. ${ }^{12}$ 
and invasiveness) to the clinical data of 787 patients with NSCLC. In addition to genetic abnormalities, a constant interplay between different oncogenic pathways aimed at activating downstream segments, irrespective of interfering blockades, has been described. ${ }^{15}$ The EGFR-activated phosphatidylinositol-4,5-bisphosphate 3-kinase catalytic subunit $\alpha$-isoform - the AKT-mTOR and the RAS/RAF/MEK pathways exemplify this concept. ${ }^{15}$

Also, the molecular processes involved with tumor dissemination to metastatic sites have been investigated to define the possible prognostic implications. Epithelial to mesenchymal transition is an example of a multistep pathway program with reciprocal interactions at a molecular level aimed at inducing phenotype alteration and functional diversification. ${ }^{16,17}$ Endowed with enhanced motility, an altered cell-to-cell relationship, and suitable structural flexibility, the cells with a mesenchymal phenotype are released from the intracellular matrix to enter the bloodstream and reach predisposed niches in distant sites. ${ }^{16,17}$ The niches are characterized by favorable microenvironments in which a mesenchymal to epithelial transition takes place to restore the original epithelial phenotype. In this setting, the sarcomatoid NSCLC histotype embodies the phenotypic changes seen in the epithelial to mesenchymal transition program. ${ }^{2,17}$

\section{MOLECULAR BIOLOGY AND SAMPLE SIZES: ISSUE OF MANDATORY RESEARCH BIOPSIES}

Expert pathologists are advocating a primary role in the individualization of treatment for patients with lung cancer inasmuch as standard biomarkers can be identified on small biopsies with similar accuracy as from surgical specimens. ${ }^{18}$ Reportedly, $1 \mathrm{~mm}^{2}$ of material obtained from the tumor can be used for RNA extraction and eventually yield a molecular diagnosis. ${ }^{19}$ However, to curb the enthusiasm toward microdissection, ${ }^{19}$ recent views seem to support moving away from fine needle aspiration biopsy as the method of obtaining an adequate diagnosis for subsequent treatment. ${ }^{2}$

The paradigm shift is obvious and might mandate innovation in perceiving the surgeon's role in the multidisciplinary management of lung cancer. One aspect could be exemplified by the request for the collaboration of thoracic surgeons in trials focused on TKIs administered in a neoadjuvant setting to patients with early-stage lung cancer. ${ }^{20}$ Furthermore, the resort to surgical "research biopsies" will increasingly be needed to obtain adequate tissue for biomolecular studies. ${ }^{21}$ Although "clinical" biopsies are aimed at altering management and might, at the same time, provide material for ongoing trials, research biopsies are obtained exclusively for research purposes without certain clinical effect. ${ }^{21}$ Nonetheless, only 1 of 5 patients accept the risk inherent to research biopsies. ${ }^{22}$ In this context, the ethical hurdles are as obvious as the potential advantages. ${ }^{21}$ Thus, the concept of surgical research biopsies is destined

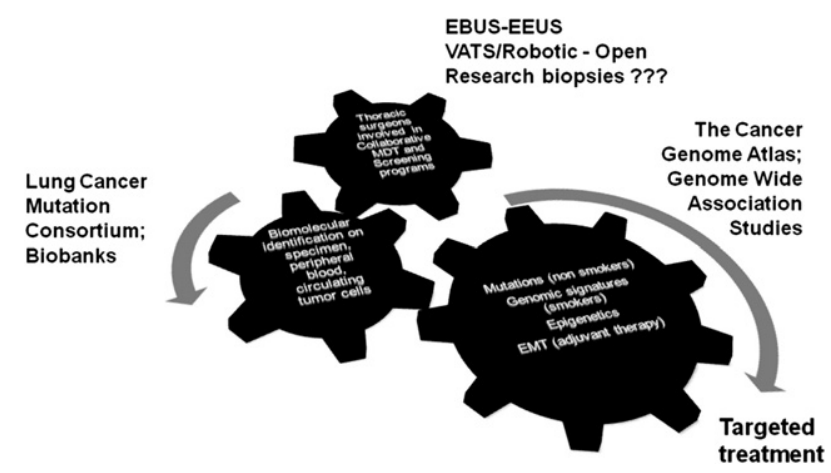

FIGURE 3. The role of the thoracic surgeon in the biomolecular era. EBUS, Endobronchial ultrasonography; EEUS, endoscopic esophageal ultrasonography; VATS, video-assisted thoracic surgery.

to raise intense controversies in the international thoracic surgical community. ${ }^{22}$ Guidelines to regulate the extent and modality for research biopsies are being implemented. ${ }^{21,22}$ As an example, research biopsies should be contemplated when a biomarker is needed to determine patient eligibility for trial entry, to finalize targeted therapy, to determine a primary endpoint of a study, or to address an issue not solvable by the analysis of archived material. ${ }^{22}$ Viable diagnostic alternatives are represented by molecular imaging, the identification of biomarkers in the peripheral blood, the molecular identification of circulating tumor cells, and, the availability of assays that can be derived from paraffin preparations in lieu of frozen section analysis. ${ }^{2}$ In the future, another breakthrough in the early diagnosis of lung cancer is likely to derive from epigenetics (ie, the study of phenotypic changes induced by mechanisms other than genetic mutations). ${ }^{2,23}$ Examples of epigenetic alterations are DNA methylation and histone deacetylation. $^{2}$ The hypermethylated promoter of tumor protein 16 can be found in the sputum of current smokers 3 years before the clinical diagnosis of lung cancer. ${ }^{2}$ Likewise, aberrant methylation of the gene locus can lead to the downregulation of cadherin 13 (T cadherin), which results in phenotypic changes and tumorigenic features similar to the activation of the epithelial to mesenchymal transition program (Figure 3). 2,24

\section{CONCLUSIONS}

In recent decades, thoracic surgeons developed an extraordinary interest in minimally invasive surgery and in not strictly technical but equally important issues such as the quality of care and risk assessment. Today, biomolecular models represent an intriguing research domain characterized by a remarkable potential for clinical correlates and innovation of the therapeutic strategies for patients with lung cancer. For the thoracic surgeon, keeping abreast of the developments in molecular biology in the field of thoracic oncology is rapidly becoming 
a professional imperative, rather than an additional educational opportunity.

\section{References}

1. Siegel R, Ward E, Brawley O, Jemal A. Cancer statistics, 2011: the impact of eliminating socioeconomic and racial disparities on premature cancer deaths. CA Cancer J Clin. 2011;61:212-36.

2. Ramalingam SS, Owonikoko TK, Khuri FR. Lung cancer: new biological insights and recent therapeutic advances. CA Cancer J Clin. 2011;61:91-112.

3. Catarino PA, Goldstraw P. The future in diagnosis and staging of lung cancer: surgical techniques. Respiration. 2006;73:717-32.

4. Vlastos F, Lacomme S, Wild P, Poulain S, Siat J, Grosdidier G, et al. Do evolving practices improve survival in operated lung cancer patients? A biobank may answer. J Thorac Oncol. 2009;4:505-11.

5. Katlic MR, Facktor MA, Berry SA, McKinley KE, Bothe A Jr, Steele GD Jr. ProvenCare lung cancer: a multi-institutional improvement collaborative. CA Cancer J Clin. 2011;61:382-96.

6. National Lung Screening Trial Research Team, Aberle DR, Adams AM, Berg CD, Black WC, Clapp JD, Fagerstrom RM, et al. Reduced lung-cancer mortality with low-dose computed tomographic screening. $N$ Engl J Med. 2011;365: 395-409.

7. Scagliotti GV, Parikh P, von Pawel J, Biesma B, Vansteenkiste J, Manegold C et al. Phase III study comparing cisplatin plus gemcitabine with cisplatin plus pemetrexed in chemotherapy-naive patients with advanced-stage non-small-cell lung cancer. J Clin Oncol. 2008;20(26):3543-51.

8. Detterbeck FC. Maintaining aim at a moving target. J Thorac Oncol. 2011;6: 417-22.

9. National Comprehensive Cancer Network $(\mathrm{NCCN})$ Guidelines ${ }^{\mathrm{TM}}$, version 3.2011. Available from: www.nccn.org. Referenced with permission from the NCCN Clinical Practice Guidelines in Oncology ${ }^{\mathrm{TM}}$ for Non Small Cell Lung Cancer, version 3.2011.

10. Stinchcombe TE, Bogart J, Veeramachaneni NK, Kratzke R, Govindan R. Annual review of advances in non-small cell lung cancer research: a report for the year 2010. J Thorac Oncol. 2011;6:1443-50.

11. Pirker R, Paz Ares L, Eberhardt WEE, et al. Epidermal growth factor receptor (EGFR) expression as a predictor of survival for first-line chemotherapy plus cetuximab in FLEX study patients with advanced non-small cell lung cancer (NSCLC). Proceedings of the 14th World Conference on Lung Cancer, Amsterdam, The Netherlands, 2011.
12. Noguchi M. Stepwise progression of pulmonary adenocarcinoma-clinical and molecular implications. Cancer Metastasis Rev. 2010;29:15-21.

13. Travis WD, Brambilla E, Noguchi M, Nicholson AG, Geisinger KR, Yatabe Y, et al. International Association for the Study of Lung Cancer/American Thoracic Society/European Respiratory Society International multidisciplinary classification of lung adenocarcinoma. J Thorac Oncol. 2011;6:244-85.

14. Mostertz W, Stevenson M, Acharya C, Chan I, Walters K, Landertthon W, et al. Age- and sex-specific genomic profiles in non-small cell lung cancer. JAMA. 2010;535-43

15. Janku F, Garrido-Laguna I, Petruzelka LB, Stewart DJ, Kurzrock R. Novel therapeutic targets in non-small cell lung cancer. $J$ Thorac Oncol. 2011;6:1601-12.

16. Denlinger CE, Ikonomidis JS, Reed CE, Spinale FG. Epithelial to mesenchymal transition: the doorway to metastasis in human lung cancers. $J$ Thorac Cardiovasc Surg. 2010;140:505-13.

17. Camerlingo R, Franco R, Tirino V, Cantile M, Rocchi M, La Rocca A, et al. Establishment and phenotypic characterization of the first human pulmonary blastoma cell line. Lung Cancer. 2011;72:23-31.

18. Pelosi G, Rossi G, Bianchi F, Maisonneuve P, Galetta D, Sonzogni A, et al. Immunohistochemistry by means of widely agreed-upon markers (cytokeratins $5 / 6$ and 7, p63, thyroid transcription factor-1, and vimentin) on small biopsies of nonsmall cell lung cancer effectively parallels the corresponding profiling and eventual diagnoses on surgical specimens. J Thorac Oncol. 2011;6:1039-49.

19. Andrews TD, Baird JW, Wallace WA, Harrison DJ. Routinely obtained diagnostic material as a source of RNA for personalized medicine in lung cancer patients. J Thorac Oncol. 2011;6:884-8.

20. Haura EB, Sommers E, Song L, Chiappori A, Becker A. A pilot study of preoperative gefitinib for early-stage lung cancer to assess intratumor drug concentration and pathways mediating primary resistance. J Thorac Oncol. 2010;5: 1806-14.

21. Peppercorn J, Shapira I, Collyar D, Deshields T, Lin N, Krop I, et al. Ethics of mandatory research biopsy for correlative end points within clinical trials in oncology. J Clin Oncol. 2010;28:2635-40.

22. Olson EM, Lin NU, Krop IE, Winer EP. The ethical use of mandatory research biopsies. Nat Rev Clin Oncol. 2011;8:620-5.

23. McDonald OG, Wu H, Timp W, Doi A, Feinberg AP. Genome-scale epigenetic reprogramming during epithelial-to-mesenchymal transition. Nat Struct Mol Biol. 2011;18:867-74.

24. Kim JS, Han J, Shim YM, Park J, Kim DH. Aberrant methylation of H-cadherin (CDH13) promoter is associated with tumor progression in primary nonsmall cell lung carcinoma. Cancer. 2005;104:1825-33. 